\title{
E-COMMERCE: Ações competitivas para o estímulo de compras no varejo
}

Roberta Manfron de PAULA ${ }^{1}$

Saulo Andrade MOREIRA ${ }^{2}$

Manuel Portugal FERREIRA ${ }^{3}$

\author{
${ }^{1}$ Doutora em Administração Professora dos Programas de Pós Graduação e MBA's da Endex / UninCor. \\ roberta.manfron@gmail.com \\ ${ }^{2}$ Bacharel em Administração. Instituto Superior de Ensino e Pesquisa de Cambuí - ISEPEC. saulo152@ hotmail.com \\ ${ }^{3}$ Programa de Pós-Graduação em Administração Universidade Nove de Julho - UNINOVE. \\ manuel.portugal.ferreira@gmail.com
}

Recebido em: 28/11/2016 - Aprovado em: 08/01/2017 - Disponibilizado em: 01/07/2017

\begin{abstract}
RESUMO:
A Internet proporciona uma extensa gama de informações e serviços, sendo fundamental para o funcionamento de inúmeras companhias, em diversos setores do mercado. Dentre estes setores, destaca-se o e-commerce, comércio que realiza operações por meio de dispositivos e plataformas eletrônicas, conectadas à rede, dispondo de praticidade, variedade de mercadorias, bons preços, além de facilidade de acesso a produtos e serviços, independentemente da região onde o consumidor se encontra. Esta pesquisa descreve a importância do e-commerce para a economia brasileira e, consequentemente, para o poder de compra. O objetivo principal deste estudo concentra-se em analisar o crescimento e o impacto do e-commerce, além de expor as estratégias utilizadas pela empresa Dafiti, objeto de estudo desta pesquisa. Os procedimentos metodológicos são caracterizados por pesquisa bibliográfica, de caráter descritivo, com abordagem qualitativa, a fim de buscar informações necessárias tanto da teoria quanto da empresa Dafiti, para justificar e ilustrar os objetivos propostos. Os principais resultados consistem na identificação de fatores estratégicos para a compreensão da relevância que o seguimento possui, na mudança de comportamento do consumidor, que pesquisa mais antes de adquirir determinado produto ou serviço, e nas alternativas exploradas pelas lojas físicas para atrair clientes, com o intuito de se adequarem a esta nova dinâmica.
\end{abstract}

Palavras-chave: E-commerce. Dafiti. Internet.

\begin{abstract}
:
The Internet provides a large gamut of information and services being fundamental to the functioning of many companies, in several market sectors. Among these sectors, show up the e-commerce business that achieve operations through devices and electronic platforms, connected to the network, offering practicality, variety of goods, good prices, over facility of access to goods and services, regardless the region where the consumer is. This research has to goal to describe the importance of e-commerce for the Brazilian economy and, consequently, for a buying power. The main goal of this study focuses on investigate the growth and impact of e-commerce, besides to show strategies used by Dafiti company, object of study of this research. The methodological procedures are characterized by analysis, descriptive with a qualitative approach searching for necessary information from both the theory and the Dafiti company, to justify and illustrate the proposed objectives. The main results consist in identifying strategic factors for understanding the relevance of the own segment in the change in consumer's behavior that research before consume a product or service, and the alternatives explored by stores with intention to attract customers, aim to with to fit to this new dynamic.
\end{abstract}

Keywords: E-commerce. Dafiti. Internet. 


\section{INTRODUÇÃO}

O estouro da bolha da Internet em 2000 mostrou que os negócios realizados pela plataforma, apesar da relativa facilidade com que podem ser montados, obedecem às mesmas regras dos outros empreendimentos, sendo que aqueles que não conseguem atrair clientes suficientes não sobrevivem. (DEGEN, 20009, SINA, 2008, HORTINHA, 2002) AInternet tem grande importância para pequenas e médias empresas, uma vez que estas a utilizam para ampliar seus canais de marketing e vendas, além de ser a base para alguns empreendimentos novos (HISRICHet al., 2009).

O conceito de $e$-commercese caracteriza como uma modalidade de negócios presente em todo o mundo, e que utiliza a Internet para realizar suas operações (CATALANI, 2006). No Brasil, o e-commerce tem menos de 20 anos, e nesse tempo já passou por muitas mudanças significativas, principalmente no quesito tecnologia. Um dos diferenciais desta modalidade de negócio está na praticidade de efetuar compras online, com lojas abertas 24 horas, facilidade na forma de pagamento, grande variedade e customização de produtos, além da facilidade de acesso em todo território nacional.

O Ibope/ NetRatings(apud Sina, 2008) indicou que em junho de 2005 o Brasil liderou o ranking de países em tempo de navegação residencial pela Internet, com a média mensal de 16:54h por pessoa. França, 15:40h; Japão, 15:35h; Estados Unidos, 14:46h e Espanha, 14:41h ficaram com as colocações seguintes nesta ordem. Os motivos indicados para esses resultados classificam o grande número de usuários jovens e o aumento do uso de banda larga, associada aos custos com pagamentos por uso limitado de horas excedentes desse limite. Isso comprova que mesmo um país ainda em desenvolvimento usa amplamente e cada vez mais esse recurso. (SINA, 2008).

Cerca de 10 anos depois, a Pesquisa Brasileira de Mídia (PBM 2015), encomendada e divulgada pela Secretaria de Comunicação Social da Presidência da República (SECOM), relata que quase metade dos brasileiros usa a internet regularmente. $\mathrm{O}$ percentual de pessoas que se conectam a rede diariamente cresceu de 26\% em 2014 para $37 \%$ em 2015. A Internet também possui um bom índice de atenção exclusiva, visto que $32 \%$ dos usuários não realizam nenhuma outra atividade no tempo em que permanecem conectados (PORTAL BRASIL, 2015).

Diante deste cenário o objetivo desta pesquisa é analisar o crescimento do ecommerce no cenário econômico brasileiro, ressaltando as principais estratégias utilizadas pelas empresas do setor para obterem êxito em seus negócios. Para isso este estudo expôs a história e evolução do conceito de $e$ commerce no Brasil, escolhendo como objeto de estudo a empresa varejista Dafiti, com representatividade significativa neste setor. 
Os principais resultados apontam que o crescimento e sucesso da empresa Dafiti no setor de e-commerce se caracteriza principalmente pela experiência e atitude visionária dos empreendedores, parcerias com grupos internacionais, inovação em serviços com a loja física e marca própria para minimizar duvidas na compra dos produtos on-line.

Este estudo contribui para um melhor entendimento da dinâmica organizacional presente no e-commerce, expondo os principais conceitos e conduzindo o leitor à reflexão de como a modalidade se tornou relevante nos últimos anos, desde a compra de roupas, sapatos, eletrodomésticos, até a assinatura de uma plataforma online para assistir uma série, ou pedir uma pizza e recebê-la em sua residência.

O trabalho está estruturado em cinco sessões. Depois da introdução, apresentamos a revisão de literatura com os conceitos de mercado e consumo, seguidos pela descrição de comércio eletrônico e sua expansão no mercado nacional. A terceira sessão descreveos procedimentos metodológicos aplicados à pesquisa e justifica a escolha da empresa Dafiti para ilustrar o cenário de $e$ commerceno contexto econômico nacional. A quarta sessão apresenta os resultados da pesquisa e seus principais achados. Por fim, tem-se a conclusão do estudo, com destaque a contribuição da pesquisa, limitações e sugestões de estudos futuros.

\section{COMÉRCIO ELETRÔNICO EM EXPANSÃO}

O comportamento dos internautas mudou bastante nas duas últimas décadas. No início, a Internet era utilizada praticamente por universitários e, posteriormente, apenas as classes A e B compravam pela rede mundial de computadores. Com a ampliação do acesso às tecnologias, a participação da classe $\mathrm{C}$ ficou muito maior, e hoje quase metade das compras online é efetuada por esse público, fazendo com que a evolução do e-commerce esteja intimamente ligada à popularização da Internet no Brasil (MITHIDIERI, 2015).

Outra evolução é a mudança na confiança em relação às lojas virtuais, pois, se antes as pessoas tinham receio de comprar e não receber, e adquiriam apenas bens mais baratos para não correr riscos de grandes prejuízos, atualmente é simples consultar a reputação das empresas na rede, permitindo compras mais seguras. Não há mais como ficar de fora do mercado. Por meio de pesquisas, sabemos que é imprescindível manter uma boa presença online, mesmo para quem não vende pela Internet. Uma venda na loja física pode começar pela Internet, com pesquisa, comparação de preço e compartilhamento de experiências de compras em redes sociais (FECOMÉRCIO, 2015).

Para Kotler (1998), os mercados eletrônicos são estimulados por recursos de informação que permitem descrever os produtos e serviços oferecidos pelos 
vendedores e facilitar a tarefa dos compradores na identificação do que necessitam ou desejam e em fazer pedidos utilizando cartão de crédito. Depois, o produto é entregue fisicamente (na casa ou escritório do comprador) ou eletronicamente (como no caso dos softwares que podem ser carregados diretamente no computador do cliente).

O crescente mercado da Internet criou uma vitrine para o mundo em que um pequeno negócio tem a mesma exposição que um grande para seus produtos, o que aumenta a concorrência. No mercado real, o varejista expõe sua mercadoria na vitrine de sua loja e a concorrência se limita às outras lojas da rua ou do shopping center. No E-commerce, o varejista enfrenta a crescente concorrência de todas as lojas virtuais que atendem a localidade onde estão seus clientes (DEGEN, 2009).

Ainda segundo Degen (2009), a compra de produtos na Internet permite que os clientes pesquisem as características e os preços dos concorrentes com muita facilidade, tendo a certeza de estar comprando pelo melhor preço ou qualidade, o que normalmente não ocorre na pesquisa em compras nas lojas físicas.

Portanto, a decisão de compra dos clientes é quase exclusivamente feita com base no preço dos produtos, disponibilidade de entrega e segurança do site. Na loja real, muitas vezes a conveniência do ponto da loja, a qualidade e a simpatia do atendimento podem superar o fator preço na decisão de compra dos clientes.

Nos últimos anos, o Brasil se deparou com o surgimento de várias empresas que exemplificam este conceito, pois exploram os mais variados nichos do varejo online, tendo como objetivo chegar rapidamente à liderança de seus mercados. São companhias como Netshoes, Privalia, Submarino e a varejista de moda online Dafiti.

\subsection{Indicadores quantitativos de compras por e-commerce}

Enquanto o varejo enfrenta os desafios impostos pelo atual cenário econômico, o $e$ commerce brasileiro continua em expansão, sendo que o segmento de moda e beleza conquista cada vez mais espaço em todo o país.

O E-commerce Brasil (2015), site especializado em comércio eletrônico, publicou um levantamento realizado pelo Serviço de Proteção ao Crédito (SPC) e a Confederação Nacional de Dirigentes Lojistas (CNDL), no qual foi possível observar que esta modalidade de negócio conta com dois itens líderes do comércio eletrônico: os calçados -o $3^{\circ}$ lugar no ranking das vendas online, e em seguida o vestuário, em $4^{\circ}$ lugar na preferência de compra virtual.

Um em cada dez entrevistados revelou algum tipo de temor em adquirir itens como sapatos, roupas e acessórios pela web, o que 
demonstra um baixo índice de rejeição no segmento digital. Entre os motivos citados pelos participantes do estudo, o que os desencoraja em adquirir esses artigos pela Internet é o receio de comprar sem a possibilidade de provar as peças, ou de não conseguir efetuar a troca e de que o produto seja diferente do que foi apresentado no site. Os itens que menos descontentam os consumidores que participaram do estudo são os perfumes e acessórios (9\%) e os cosméticos (10\%), já que a probabilidade de o produto obtido ser diferente do apresentado é mínima. (E-COMMERCE BRASIL, 2015).

O estudo ainda revelou que dos 24,9 milhões de consumidores do nicho, 53\% são mulheres e $47 \%$ são homens. A faixa etária dominante nas compras online dos produtos de moda e beleza é de 25 a 34 anos (40\%), seguida pelos consumidores de 35 a 49 anos $(31 \%)$ e os de 18 a 24 anos (15\%), evidenciando que os jovens estão cada vez mais adeptos em relação ao E-commerce. $\mathrm{O}$ público está dividido entre as classes A /B $(51 \%)$ e C/D/E (49\%). (E-COMMERCE BRASIL, 2015).

Segundo Majczak (2015), há uma série de fatores que colocam o varejo online como uma das atividades mais lucrativas, sendo que os mais consideráveis são o aumento ao acesso à Internet, a ampliação da qualidade da rede, o crescimento da familiaridade dos consumidores nas transações online e as diversas formas de pagamento. Há muito espaço para desenvolvimento da área. Os varejistas virtuais podem realizar estudos e aproveitar o aspecto cultural de seus consumidores. Como exemplo, é possível citar o varejo de moda, que precisa vencer a barreira cultural de o cliente ainda desejar experimentar o item que lhe interessa. O desempenho financeiro positivo está estritamente atrelado ao ponto de tornar comum a aumento na compra de roupas, calçados e acessórios pela Internet (MAJCZAK, 2015).

O número de pedidos feitos via Internet, em 2014, foi de 103,4 milhões, quantidade $17 \%$ maior que o registrado no ano anterior (88,3 milhões), sendo que 61,6 milhões de pessoas já fizeram alguma compra online no Brasil. Destes, 51,5 milhões fizeram pelo menos uma compra em 2014 e as demais (10,1 milhões) não compraram pela Internetem 2015. Em média, foram realizadas duas compras por consumidor no decorrer do ano. No ano de 2015, o faturamento cresceu cerca de $20 \%$, o que evidencia a viabilidade do setor e sua importância para o ciclo econômico do país (E-bit, 2015).

O SEBRAE (2015), em parceria com a E-commerce Brasil, desenvolveu em 2014 a Primeira Pesquisa Nacional do Varejo Online, com uma amostra de 668 respondentes, distribuídos entre as cinco regiões do país, tendo confiança de $95 \%$ e margem de erro de 4,0\%.A pesquisa teve como objetivo analisar a situação das empresas que atuam no setor de 
e-commerce dentro do território nacional.Os dados revelam que uma em cada três empresas opera exclusivamente online. A média de funcionários na operação do $e$ commerce é de sete pessoas, sendo que 58,3\% das empresas possuem até três funcionários.67,4\% das empresas participantes foram criadas entre 2011 e 2014, dado que demonstra o crescimento do setor nos últimos anos.Entre as empresas participantes, $41 \%$ foram criadas entre $2013 \mathrm{e}$ 2014. Previsivelmente, as regiões Sudeste e Sul representam $84,1 \%$ das empresas de $e$ commerce no Brasil.Não por acaso, os principais destinos de vendas estão localizados nos estados de São Paulo, Rio de Janeiro, Minas Gerais, Rio Grande do Sul e Paraná.Estes cinco estados representam aproximadamente $65,3 \%$ do PIB nacional (SEBRAE, 2015).

A pesquisa aponta diferenças de faturamento entre empresas que operam com E-commerce Misto (incorporado a plataformas online e estabelecimentos físicos) e E-commerce Puro (exclusivamente online). Empresas que trabalham com o E-commerce Misto atingem um faturamento mais alto, visto que sua abrangência é maior.O faturamento que é direcionado para investimentos na área de marketing correspondem, em média, a $13,8 \%$ sobre o valor total. Dentre os investimentos realizados nesta área, destaca-se ações em mobilemarketing, (inserção da marca no cotidiano do cliente), desenvolvendo aplicativos para smartphones, por exemplo, utilizados para prestar algum tipo de serviço vinculado às atividades que a organização desenvolve (E-COMMERCE NEWS, 2015).

Juntamente com o mobile marketing, temos como exemplos de investimentos em marketing a estratégia que utiliza localização para envio de conteúdo personalizado, denominada location based marketing, e a mídia programática, que usa espaços de sites em vários segmentos e redes sociais para fazer anúncios (KEHDI, 2015).

Com foco na personalização, o email marketing também é um excelente canal para criar e manter relacionamento com clientes, uma vez que, ao adquirirem determinado produto, concedem informações valiosas à empresa, como suas preferências de compras, e abrem caminhos para o envio de e-mails com ofertas, novidades, tutoriais e vantagens nas compras (SPITALIERE, 2015).O E-mail é o canal de atendimento mais utilizado, seguido pelo telefone e redes sociais. $\mathrm{O}$ aplicativo Whatsapp também se tornou um canal de atendimento ao cliente, e já é utilizado por $18 \%$ das empresas participantes (SEBRAE, 2015).

Através do marketing, o comércio eletrônico ajusta investimentos de forma mais rápida e precisa, tornando os resultados fáceis de serem mensurados e, por consequência, mais tangíveis. Em tempos de crise, este processo exerce uma função importante para 
que o mercado digital busque caminhos propícios para sofrer poucos impactos negativos (KEHDI, 2015).

Com relação aos meios de entregas dos produtos, os correios são os mais solicitados, seguidos pelas transportadoras privadas. Foi possível constatar que $19,1 \%$ dos pedidos geram atendimento pós-venda (SEBRAE, 2015). O custo com logística reversa representa, em média, $6,4 \%$ sobre o faturamento total. Os principais motivos para a logística reversa são: defeito do produto, arrependimento e produto inadequado. $\mathrm{O}$ item defeito do produto compreende as falhas no sistema de qualidade da produção, que geram posteriores prejuízos às companhias, visto que a mesma deve evitar a insatisfação do cliente, efetuando a troca da mercadoria. Já o item arrependimento refere-se a consumidores que compram de maneira compulsiva, sem necessidade, e acabam devolvendo o produto. A respeito dos clientes que compram produtos sem conhecer suas especificações, correm o risco de se deparar com um produto inadequado à sua necessidade, acarretando a eventuais reversões (SEBRAE, 2015).

\section{MÉTODO}

Esta pesquisa possui caráter descritivo, e utiliza uma abordagem qualitativa amparada por pesquisa bibliográfica, seguida de pesquisa documental com a finalidade de desenvolver o tema proposto amparado por material já elaborado, constituído principalmente por livros, artigos científicos, relatórios e pesquisas publicadas por instituições especializadas.(GIL, 2008).

Através da análise do tema e da empresa escolhida para ilustrar o assunto, foi possível realizar um estudo detalhado, com o propósito de compreender os objetivos da pesquisa, e sua relevância acadêmica e social.

\subsection{Lócus da Pesquisa - DAFITI}

A Dafit ifoi criada em janeiro de 2011 por quatro empreendedores com idade entre 28 e 31 anos e formados em escolas de negócios como Harvard e Insead - os alemães Malte Horeyseck e Malte Huffmann, o francês Thibaud Lecuyer e o brasileiro Philipp Povel. A empresa se destaca no cenário nacional e internacional do setor de $e$ commerce, sendo exemplo de modelo de negócio bem-sucedido no Brasil(LEAL, 2015). No seu ramo de atividade, a Dafiti consegue explorar várias áreas, desde a venda de produtos à prestação de consultoria para outras empresas, e produção para a marca própria, com a proposta de ter uma loja física para exposição de produtos e interatividade com seu público alvo (DAFITI, 2016).

\section{RESULTADOS}

Segundo Fernando de La Riva, especialista em negócios digitais e diretorexecutivo da Concrete Solutions, empresa especializada em desenvolvimento de softwares para comércio eletrônico, a Dafiti é 
a empresa online de crescimento mais rápido do Brasil, e um de seus diferenciais está na natureza dos sócios, que não são apenas brasileiros, o que faz com que eles tenham experiência no exterior, e consigam implantar um modelo que é sucesso fora do país, promovendo crescimento rápido e taxa de aceitação muito alta (MUNIZ, 2015).

$\mathrm{O}$ crescimento da Internet, e seu impacto em nosso cotidiano, ocasionaram atrativas oportunidades para que os empreendedores criassem formas de expandirem suas marcas em pouco tempo, transmitindo credibilidade e confiabilidade ao consumidor (ENDEAVOR BRASIL, 2015).

Isto ocorreu com a Dafiti, criada para atender os públicos das classes $\mathrm{A}$ e $\mathrm{B}$, e que, posteriormente, passou a vender para a classe $\mathrm{C}$, que se tornou o novo foco da loja virtual. Com isso, a propaganda também deixou de ser apenas digital e chegou à TV. Segundo Philipp Povel, sócio-diretor da Dafiti, a empresa sempre anunciou na área digital, e enfatiza que o Google e o Facebook são mercados muito importantes para esta estratégia. Todavia, percebeu-se que a TV gera mais confiabilidade para a marca no Brasil, onde é extremamente usual entre a classe C (MUNIZ, 2015).

Pode-se analisar que a empresa Dafiti soube escolher de maneira adequada suas estratégias, gerando oportunidades a milhares de colaboradores e se tornando referência no segmento varejista de moda.
A Dafiti tem uma fórmula europeia de negócios e entrou no país em busca de um mercado que ainda não estava sendo explorado, mas com potencial para abrigar um grande público. O empreendimento deu certo, e atualmente a empresa já expandiu suas atividades para Argentina, Chile, Colômbia e México, com o objetivo de levar o mesmo sucesso que obteve no Brasil, onde recebe 9 milhões de visitas por mês em seu site (MUNIZ, 2015).

\subsection{Dados econômicos e de crescimento da empresa}

Em três anos, a empresa chegou a uma receita avaliada em 800 milhões de reais e assumiu a liderança do mercado de moda na Internet brasileira. Neste período, recebeu 660 milhões de reais em investimentos de grupos internacionais, como o fundo alemão Rocket e o Banco Mundial. Além de sapatos, seu primeiro produto comercializado, passou a vender roupas, artigos esportivos e objetos de decoração, num total de 75.000 itens (LEAL, 2015).

O número total de encomendas chegou a 4,4 milhões em 2014, ou, $34 \%$ superior aos pedidos em 2013, sendo que esta quantia, ao todo, representa um volume bruto de mercadorias da ordem de R \$ 626 milhões. Já o total de clientes que adquiriram ao menos um produto no e-commerce da empresa em 2014 foi de 3,07 milhões de pessoas. 
A formação do Global Fashion Group (GFG), grupo de moda associado a empresas do segmento, em setembro de 2014, foi mencionado no balanço como um dos grandes acertos da Dafiti em 2014. Na ocasião, a companhia se associou a outras quatro grandes organizações da moda online: Jabong (India), Lamoda (Rússia), Namshi (Oriente Médio) e Zalora (Sudeste da Ásia e Austrália). Ao totalizar os países de atuação, o Grupo compreende 27 mercados, além de nove milhões de clientes ativos e mais de um bilhão de euros no volume bruto de produtos (E-COMMERCE NEWS, 2015).

A estratégia da Dafiti em 2014,foi fundamentada em investimentos com logística e desempenho, além da implantação do sistema SAP, e lançamentos recentes da marca, como a Dafiti Lei, primeira loja física temporária na Oscar Freire, em São Paulo, e a primeira coleção própria, Dafiti Coletem, considerados oportunidades de crescimento da empresa (VAZ, 2015).

\subsection{Novas Propostas para Atrair Clientes}

Com o anseio de conquistar esta confiança, a Dafiti inaugurou, no início de Março de 2015, sua primeira loja física, a Dafiti Lei, na esquina da Oscar Freire com a Rua da Consolação, um dos centros mais badalados da moda paulistana, conforme consta no Anexo A, e tem como proposta levar seus produtos e serviços para públicos diversos, incluindo pessoas que ainda tem receio de fazer compras pela Internet (VAZ, 2015).

Segundo Malte Hoffman, sócio-diretor da Dafiti, o conceito se torna diferente do encontrado em lojas convencionais, pois o modo de comprar é inovador. A primeira coisa a fazer ao entrar na loja é acessar o aplicativo da Dafiti (exemplo de móbile marketing), identificar que está na loja e, depois, escolher a peça que será provada, por meio da leitura digital do código de identificação do produto, sendo que o pagamento é feito via web, e as compras são entregues em casa. Com três andares, dois para o público feminino e um para o masculino, o endereço conta com 15 funcionários e uma oferta alta de opções, expondo 1.500 peças, todas renovadas a cada 15 dias (VAZ, 2015).

Grande parte dos itens faz parte da marca própria, e este fator se torna mais um diferencial que a empresa utiliza perante seus concorrentes, sejam eles diretos ou indiretos, além de criar expressividade para o nome da companhia dentro do mercado nacional, visto que usar uma marca é uma maneira de distinguir produtos na mente de compradores potenciais, que podem dedicar um esforço extra e gastar dinheiro adicional para comprar uma determinada marca.Assim como as grandes varejistas espalhadas pelo mundo, a Dafiti investe nesta estratégia, e detém uma equipe de 20 pessoas para criar roupas, acessórios e calçados que compõem a Dafiti 
Collection, com o objetivo de vender produtos que tenham qualidade, estilo e preço justo (VAZ, 2015).

Um dos métodos utilizados pela Dafiti para alcançar a fidelização de clientes é o $e$ mail marketing, que segundo Metzen (2015), especialista em Ciência da Computação e fundador da Conceptho, empresa especializada em serviços web, é uma ferramenta simples, com décadas de experimentação no mercado, que demonstra interesse e desperta a confiança do consumidor.

Ainda conforme Metzen (2015), o $e$ mail marketing permite que, através do histórico de compras, seja traçado um perfil de cada consumidor. A partir disso, podem ser enviados apenas e-mails comprodutos realmente relevantes para aquele consumidor.

Com esta análise minuciosa de comportamento, é possível obter dados que irão contribuir para adaptar cada vez mais uma campanha precisa e direcionada. Em tempos de forte impessoalidade, esta estratégia pode demonstrar interesse em atrair o cliente, tornando-se determinante para a venda do produto (METZEN, 2015).

Além disso, ao traçar o perfil do consumidor, a empresa consegue resultados mais rápidos e eficazes, visto que a compra de determinados produtos ou marcas são necessidades muitas vezes levadas a um nível emocional e não necessariamente a um nível racional (COBRA, 2009).

\subsection{Investimento em inovação tecnológica}

Trocar a base de um e-commerce é uma das alterações mais vulneráveis e complexas que uma empresa do setor pode sofrer. A Dafiti, no entanto, não esperava que este processo se tornasse um grande transtorno, uma vez que houve erros na integração de todos os sistemas, o que ocasionou falhas e atrasos no atendimento de até $3 \%$ dos clientes, porcentagem alta, visto que estamos tratando de um e-commerce que soma 50 milhões de visitas mensais (BIGARELLI, 2015).

De acordo com Vaz (2015), no ano de 2014, a Dafiti esteve no topo das empresas mais reclamadas na web, o que gerou uma multa de R\$ 344 mil do Procon.

As queixas que chegaram ao órgão são semelhantes às que constam no Reclame Aqui, referindo-se a não entrega de mercadorias, impossibilidade de comunicação com o atendimento da empresa, inexistência de atualização do status do pedido e não cumprimento da política de trocas e devoluções (BIGARELLI, 2015).

Os problemas foram ocasionados pela migração de sistemas da companhia para o SAP, software alemão de gerenciamento para empresas de grande, médio e pequeno portes, utilizado em vários países, e que foi planejada pela Dafiti por aproximadamente nove meses, sendo executada em junho daquele ano. Todo o processo foi normalizado em pouco tempo, 
mas a repercussão dos problemas se manteve por alguns meses.

A companhia investiu 20 milhões de reais na troca de sistemas, integração da parte logística e aumento de funcionários do setor de atendimento ao cliente, de 200 para quase 500 pessoas, sendo que a estratégia da empresa se faz necessária para cortar custos ao curto prazo, com a personalização de algumas áreas e o compartilhamento da estrutura com futuros clientes da Dafiti Setores, segmento da companhia que prestará serviços de consultoria para outras empresas (VAZ, 2015).

Mesmo com os imprevistos e dificuldades de implantação e mudanças em seu sistema operacional, a empresa conseguiu resultado positivo em 2014, com faturamento de aproximadamente $\mathrm{R} \$ 592$ milhões, e para 2015 a expectativa é de que os efeitos da recessão econômica não diminuam o progresso, visto que seu desempenho é satisfatório (E-COMMERCE NEWS, 2015).

\subsection{Consultoria para Empresas do Setor}

$\mathrm{Na}$ parte de consultoria para empresas, batizada de Dafiti Setores, a companhia já agencia mais de 30 lojas, como Andarella, Santa Lolla, Lilly's Closet, Cavalera, Capodarte, Dumond, Penalty, Rockstter, Zapälla, Onbongo, Tapout, Ortopé, Desigual, Vizzano, Canal Concept, Hawaian Dreams, Grendha, Ipanema, Zaxy, Esdra, Rider, Cartago, Grendene, Grendene Kids, Kelme,
G-Shock, Pretorian, Forum, Sommer, Triton e Colcci, além de gerenciar toda a loja virtual da marca de surf e skate Star Point (VAZ, 2015).

Segundo Philipp Povel, até 9\% da receita total da empresa vem da venda desses serviços, sendo que o mesmo acredita que o potencial para este mercado é ainda maior. No modelo, a Dafiti oferta para empresas que querem começar a vender pela Internet, desde todo o conhecimento do setor até a estrutura da loja online, cuidando da manutenção, design, marketing, processamento de pagamentos, desenvolvimento, relatórios, suporte logístico e atendimento aos consumidores (VAZ, 2015).

É possível perceber, através de análises às lojas virtuais incorporadas a esta nova concepção online, que a Dafiti busca utilizar a mesma plataforma de seu site para atender estas empresas, fato que lhe proporciona maior facilidade ao prestar o auxílio necessário às companhias, pois o processo se torna padrão, mesmo que os sites funcionem separadamente.

\subsection{Concorrência no Setor}

O comércio eletrônico brasileiro tem, desde sua origem, setores sobrecarregados de investimentos, e outros pouco explorados, de maneira que a maior rivalidade sempre esteve no varejo de eletroeletrônicos, atualmente dominado pela $\mathrm{B} 2 \mathrm{~W}$, proprietária da Americanas.com, e pela Cnova, detentora das 
operações online de Casas Bahia e Ponto Frio. Setores considerados nichos de mercado puderam crescer sem tantos transtornos, e seu maior desafio era convencer os clientes a adquirir produtos pela Internet. Foi o que ocorreu, durante anos, nos segmentos de moda e artigos esportivos, liderados por Dafiti e Netshoes, respectivamente (AMORIM, 2015).

Para se ter uma ideia, segundo o Google, mais de sete milhões de buscas mensais são realizadas por palavras relacionadas à Dafiti e Netshoes, informação que comprova o êxito na estratégia de comunicação e promoção das empresas (LIPPERT, 2015).

Apesar de trabalharem com produtos similares, o mercado nunca havia se atentado à possibilidade de uma eventual concorrência direta entre ambas, até o momento em que a Dafiti começou a investir na área de artigos esportivos, com a criação da Dafiti Sports, e a Netshoes fez o mesmo na área da moda, iniciando uma inédita concorrência no comércio eletrônico brasileiro (AMORIM, 2015).

A Netshoes foi criada mais de uma década antes da Dafiti, em 2000, pelo exvendedor de sapatos Marcio Kumruian, possuindo fundos de investimento do grupo Tiger Global. Seu faturamento chegou a R\$ 1,2 bilhão em 2014.

De acordo com Amorim (2015), a maior diferença da Dafiti Sports em relação à concorrente é oferecer grande variedade de roupas e acessórios de surfe e skate. Atualmente, a plataforma possui a média de 700.000 visitantes por mês, que equivale a cerca de $8 \%$ do total de visitantes da Dafiti e $2 \%$ da Netshoes.

Com relação ao mercado de moda online, liderado pela Dafiti, Amorim (2015) destaca que a competição se estabeleceu em dezembro de 2014, no momento em que a Netshoes investiu R \$ 25 milhões para criar a plataforma de moda online, chamada Zattini, que possui como principal executiva Márcia Lima, ex-funcionária da principal concorrente. Ela lidera uma equipe de 35 funcionários, muitos deles vindos de varejistas de moda, como C\&A e Renner, que utilizam um andar na sede da Netshoes, em São Paulo, com as áreas comercial e de marketing. Já as áreas de finanças, logística e tecnologia são compartilhadas com a estrutura da Netshoes.

Ainda que disputem o mesmo público, Dafiti e Zattini não possuem as mesmas estratégias, uma vez que a primeira contém sua própria coleção, que atualmente corresponde a $20 \%$ das vendas, e tem como objetivo chegar aos 50\% até 2017. Outra estratégia da companhia para impedir o crescimento da concorrente é utilizar o poderio do grupo GFG, realizando acordos exclusivos com empresas internacionais, como a Benetton, localizada na Itália, e a 
Mango, que tem sede na Espanha (AMORIM, 2015).

Porém, não é só com a Zattini que a Dafiti deve se preocupar. A varejista holandesa $\mathrm{C} \& \mathrm{~A}$, que voltou ao e-commerce em janeiro de 2015, e a companhia Privalia, multinacional que busca ofertar descontos diferenciados aos consumidores cadastrados em seu site, apresentam potenciais para pleitear a liderança do mercado brasileiro. Para exemplificar esta situação, a C\&A tem como meta para 2015 faturar mais em vendas na loja online do que em qualquer loja física no país(AMORIM, 2015).

Com o intuito de inibir este crescente quadro de concorrência, a Dafiti fortaleceu sua presença de mercado em julho de 2015, com a aquisição das lojas online Kanui, de produtos esportivos, e Tricae, líder no segmento de roupas e brinquedos para bebês e crianças. Esta manobra evidencia o interesse da empresa, e do Global Fashion Group (GFG), em expandir suas atividades na América Latina. Para Wilson Cimino, CEO da Tricae, a operação garantirá um melhor serviço de entrega para seus clientes, uma vez que a Dafiti já possui um sistema logístico muito eficaz, que poderá ser incorporado às demais companhias, contribuindo de forma satisfatória para aumentar a abrangência de clientes, que poderão adquirir mais de $30 \mathrm{mil}$ produtos disponíveis no site da empresa (PEQUENAS EMPRESAS E GRANDES NEGÓCIOS, 2015).
Inicialmente, as três empresas irão manter seus próprios sites, marcas e culturas atuais. Vale ressaltar que, reunidas, as três companhias faturaram R\$ 773 milhões em 2014. A operação evidencia o objetivo do grupo na América Latina, que é de crescer cada vez mais na região. Com esta negociação, o GFG passa a empregar aproximadamente 3.100 funcionários, sendo 2.400 brasileiros, e possui cinco milhões de clientes em toda a América Latina(PEQUENAS EMPRESAS E GRANDES NEGÓCIOS, 2015).

\section{DISCUSSÃO E CONSIDERAÇÕES FINAIS}

Nos últimos anos, o e-commerce se tornou uma atrativa modalidade de negócios, conquistando investidores, fornecedores e clientes em várias partes do mundo. No Brasil, sua representatividade econômica, em meio à forte recessão, comprova ser viável aplicá-lo em diversos setores, sendo que grande parte das empresas foram criadas nos últimos dez anos e estão em processo de crescimento, com um amplo nicho de mercado a ser explorado.

$\mathrm{O}$ estudo permitiu que fossem identificados fatores estratégicos para a compreensão da relevância que o segmento possui, com foco no cenário varejista do país, no qual é plausível dizer que o comércio eletrônico se conserva otimista e em pleno crescimento diante de uma conjuntura que 
abala a estrutura financeira, em âmbito nacional, buscando obter cada vez mais êxito em suas negociações, com o intuito de atingir públicos de diversas classes, por meio de variedade de produtos, preços diversificados e difusão do processo de compra através de dispositivos móveis, como tablets e smartphones.

Esta difusão, alinhada à mudança de comportamento do consumidor, devido ao processo de crise, no qual as pessoas pesquisam mais antes de adquirir determinado produto ou serviço, faz com que o $e$ commerce tenha vantagens diante das lojas físicas, tanto em grandes centros, onde o uso da tecnologia é comum, quanto no interior, em que o acesso a mercadorias ou serviços é restrito, visto a dinâmica social e econômica que inviabilizam este alcance.

A empresa Dafiti elucida este crescimento, uma vez que, em menos de seis anos, atraiu mais de 660 milhões de reais em investimentos, com uma receita de 800 milhões de reais, 75.000 itens em estoque e 1.800 funcionários, alcançando 9 milhões de visitas mensais em seu site no Brasil. Também é oportuno citar que a prestação de serviços para empresas do setor, através de consultorias, se torna uma estratégia favorável à otimização dos recursos que a companhia possui, em razão de gerar mais receita sem que haja a necessidade de altos investimentos em estrutura, pois a base deste processo se encontra dentro da própria organização e é transformada em uma verdadeira extensão do trabalho já existente.

Cabe às lojas físicas buscarem alternativas para maior atratividade de clientes, incluindo a formação de parcerias com o e-commerce, tendo em vista o estabelecimento de mudanças de hábitos dos consumidores, como podemos exemplificar através da Dafiti Live, que integrou as duas modalidades de negócio para melhor aceitação de mercado. Por meio deste recurso, torna-se possível aumentar o rendimento destas modalidades, pois as estruturas serão potencializadas, o número de empregos gerados será maior, o público a ser atingido terá condições de se expandir e, consequentemente, os fornecedores terão condições de reduzir preços e acrescentar benefícios, revertidos em melhorias para os lojistas e consumidores finais.

\section{Limitações da pesquisa}

Dentre as principais limitações encontradas no decorrer desta pesquisa, destaca-se a escassez de detalhes nas informações sobre a empresa Dafiti, aumentando o número de sites consultados para o desenvolvimento do estudo. Outro empecilho se refere à confiabilidade das informações averiguadas, pois as quantidades de dados, presentes na Internet, muitas vezes não são oriundas de fontes fidedignas, prejudicando a coleta de dados e necessitando de uma análise mais criteriosa na busca de 
elementos verídicos para apresentação e

análise dos resultados.

\section{Sugestões para pesquisas futuras}

Explorar os avanços tecnológicos na área de e-commerce, as mudanças no comportamento dos clientes e a integração entre lojas virtuais e físicas, que já se tornou uma tendência de mercado, posto que as organizações possuam o dever de permanecerem atentas às transformações tecnológicas, sociais e econômicas que o ambiente externo sofre ao longo do tempo, a fim de inovar os produtos e serviços ofertados e se manterem cada vez mais competitivas. Essas percepções são bons direcionamentos para pesquisas futuras neste setor.

\section{REFERÊNCIAS}

\section{AMORIM, Lucas. Para Dafiti e Netshoes, a} briga é de vida ou morte. Disponível em: <http://exame.abril.com.br/revistaexame/edicoes/1092/noticias/para-dafiti-enetshoes-a-briga-e-de-vida-ou-morte> Acesso em 30 de Agosto de 2015.

\section{BIGARELLI, Bárbara. Dafiti tem falha no} sistema e bate recorde de reclamações.

Disponível em:

<http://epocanegocios.globo.com/Informacao/Dile mas/noticia/2014/08/dafiti-tem-falha-no-sistemae-bate-recorde-de-reclamacoes.html > Acesso em 27 de Setembro de 2015.

CATALANI, Luciane, André Kischinevsky, Eduardo Ramos, Heitor Simão. E-commerce. $2^{\mathrm{a}}$ Edição Revisada. Rio de Janeiro: Editora FGV, 2006.

COBRA, Marcos. Marketing Básico. $4^{\mathrm{a}}$ Edição, p. 37. São Paulo: Editora Atlas, 2009.
DAFITI. Site Oficial. Disponível em https://www.dafiti.com.br/?placeholder\&gclid $=\mathrm{Cj}$ wKEAiAmdXBBRD0hZCVkYHTI20SJACWsZj 91XC0C7r6ZdtchQDYwf1MkW7maiY93CksKfgoJqnFhoC PQjw wcB. Acesso em 10 de março de 2016.

DEGEN, R. J. O empreendedor: empreender como opção de carreira. São Paulo: Pearson Prentice Hall, 2009.

E-BIT. Webshoppers 2015, o relatório mais sólido e respeitado do comércio eletrônico. Disponível em:

$<$ http://www.ebit.com.br/webshoppers?webShopp er.periodicityEmail=S\&urlDownloadType=pt_BR > Acesso em 30 de Agosto de 2015.

\section{E-COMMERCE BRASIL. Comércio eletrônico} ganha mais importância. Disponível em: $<$ http://www.ecommercebrasil.com.br/noticias/co mercio-eletronico-ganha-mais-importancia/> Acesso em 21 de Março de 2015

\section{E-COMMERCE NEWS. Ações em mobile} marketing ganham relevância. Disponível em: <http://ecommercenews.com. $\mathrm{m}-$ mobile-marketing-ganham-re 06 de Setembro de 2015.

\section{ENDEAVOR BRASIL. Marketing digital para} empreendedores. Disponível em:

$<$ http://materiais.resultadosdigitais.com.br/marketi ng-digital-para-empreendedores > Acesso em 13 de Setembro de 2015.

\section{FECOMÉRCIO MG. E-Commerce é} considerado seguro e confiável. Disponível em: <http://www.fecomerciomg.org.br/2015/07/ecommerce-e-considerado-seguro-e-confiavel/> Acesso em 15 de Agosto de 2015.

GIL, Antônio Carlos. Como elaborar projetos de pesquisa. $4^{a}$ edição. São Paulo: Editora Atlas, 2008.

KEHDI, Túlio. Análise: A importância de investir em marketing no mercado digital. Disponível em <http://www.administradores.com.br/noticias/mar keting/analise-a-importancia-de-investir-emmarketing-no-mercado-digital/100052/> Acesso em 06 de Setembro de 2015. 
HISRICH, Robert D., MICHAEL P. PETERS, Dean A. SHEPHERD. Empreendedorismo. $7^{\text {a }}$ Edição, p. 182. Porto Alegre: Editora Bookman, 2009.

HORTINHA, Joaquim. X-Marketing. $1^{\text {a }}$ edição. Lisboa: Editora Silabo, 2002.

KOTLER, Philip. Administração de marketing: análise, planejamento, implementação e controle. $5^{\text {a }}$ Edição, p. 625. São Paulo: Editora Atlas, 1998.

LEAL, Ana L. Bolha.com.br? Lojas online crescem, mas não lucram. Disponível em: $<$ http://exame.abril.com.br/revistaexame/edicoes/1062/noticias/bolha-com-br> Acesso em 21 de Março de 2015.

\section{LIPPERT, Dener. Vender moda online é} lucrativo? Disponível em:

$<$ http://www.administradores.com.br/mobile/artig os/marketing/vender-moda-online-e-

lucrativo/88353/> Acesso em 07 de Setembro de 2015.

MAJCZAK, Christian. E-commerce está na contramão da economia nacional. Disponível em: 〈http://www.go4.com.br/noticias.php> Acesso em 28 de Agosto de 2015.

METZEN, André. Três maneiras de usar o email marketing no seu e-commerce. Disponível em:

<http://www.ecommercebrasil.com.br/artigos/3maneiras-de-usar-o-e-mail-marketing-no-seu-ecommerce/> Acesso em 24 de Maio de 2015.

MITHIDIERI ,Thiago. A evolução do ecommerce no Brasil. Disponível em: $<$ http://www.ecommercebrasil.com.br/artigos/aevolucao-do-e-commerce-no-brasil/> Acesso em 03 de Abril de 2015.

MUNIZ, Leticia. Dafiti, o fenômeno que ganhou espaço no e-commerce. Disponível em: <http://exame.abril.com.br/negocios/noticias/dafit i-o-fenomeno-que-ganhou-espaco-no-ecommerce> Acesso em 01 de Abril de 2015.

\section{PEQUENAS EMPRESAS E GRANDES}

NEGÓCIOS. Dafiti anuncia compra dos ecommercesTricae e Kanui. Disponível em: $<$ http://revistapegn.globo.com/Dia-a$\mathrm{dia} /$ noticia/2015/07/dafiti-anuncia-compra-dos-e- commerces-tricae-e-kanui.html> Acesso em 07 de Setembro de 2015.

PORTAL BRASIL. Brasileiros ficam mais tempo conectados do que assistindo TV. Disponível em:

<http://www.brasil.gov.br/governo/2014/12/brasil eiros-ficam-mais-tempo-conectados-queassistindo-tv> Acesso em 29 de Agosto de 2015.

\section{SEBRAE MG. Primeira Pesquisa Nacional do} Varejo Online. Disponível em: <https://www.sebraemg.com.br/atendimento/bibli otecadigital/documento/diagnostico/primeirapesquisa-nacional-do-varejo-online> Acesso em 16 de Agosto de 2015.

SINA, Amalia. Marketing Global: Soluções Estratégicas para o Mercado Brasileiro. $1^{\text {a }}$ Edição, p. 5 a 16. São Paulo: Editora Saraiva, 2008.

SPITALIERE, Juliana. E-mail marketing e redes sociais: integração ou aversão? Disponível em <http://www.administradores.com.br/artigos/mark eting/email-marketing-e-redes-sociais-integracaoou-aversao/88712/> Acesso em 06 de Setembro de 2015.

VAZ, Tatiana. Dafiti lança coleção de roupas e abre $1^{a}$ loja em São Paulo. Disponível em: $<$ http://exame.abril.com.br/negocios/noticias/dafit i-lanca-colecao-de-roupas-e-abre-1a-loja-em-saopaulo> Acesso em 05 de Abril de 2015.

VAZ, Tatiana. Dafiti terá marca própria e consultoria para varejistas. Disponível em: $<$ http://exame.abril.com.br/negocios/noticias/dafit i-tera-marca-propria-e-consultoria-paravarejistas> Acesso em 01de Abril de 2015. 